\title{
Does Sleep Education Change Sleep Parameters? Comparing Sleep Education Trials for Middle School Students in Australia and New Zealand
}

\author{
S. Blunden ${ }^{*}, 1$, G. Kira ${ }^{2}$, M. Hull ${ }^{3}$ and R. Maddison ${ }^{2}$ \\ ${ }^{1}$ Appelton Institute, Central Queensland University, Australia \\ ${ }^{2}$ Clinical Trials Research Unit, University of Auckland, New Zealand \\ ${ }^{3}$ School of Population Health, University of Auckland, New Zealand
}

\begin{abstract}
Background: Adolescents suffer daytime consequences from sleep loss. Sleep education programs have been developed in an attempt to increase sleep knowledge and/or duration. This paper presents data from three trials of the Australian Centre for Education in Sleep (ACES) program for adolescents.

Methods: The ACES program was delivered to 69 Australian adolescents in a pre-post cross-sectional design (mean age 15.2) and 29 New Zealand adolescents in a randomised control trial (mean age 14.8 years). Assessments in sleep parameters were undertaken at baseline and post intervention.

Results: Where sleep knowledge was evaluated (Australian trials), significant improvements were shown in all trials (All $\mathrm{p}<0.05$ ). Where sleep duration was assessed (New Zealand trial) significant improvements were found in week and weekend sleep duration $[\mathrm{F}(1,27)=4.26, p=0.04)$. Both, students and teachers found the program feasible, interesting, and educational.

Conclusions: ACES sleep education programmes can improve both sleep knowledge and sleep duration in adolescents. Improving the programme so sleep knowledge attained equates to actual sleep behaviour change are areas for future direction. Collectively these findings provide encouraging signs that adolescents can improve their sleep knowledge and behaviour with sleep education which bodes well for sleep-related health and psycho-social issues.
\end{abstract}

Keywords: Sleep education, behaviour change, adolescents, sleep duration, sleep knowledge.

\section{INTRODUCTION}

Sleep problems in adolescents, as classified by the International Classification of Sleep Disorders 2nd ed [1] including both physiologically and behaviourally based sleep problems [2], are estimated to range between $11-30 \%$ of adolescents [3-5]. There is also much evidence to suggest that these sleep problems may not be benign, even in those without a medical aetiology. Negative daytime consequences of sleep disorders include inattention, poorer memory capacity, behavioural problems including irritability, emotional lability, problematic behaviour, psychopathology, hyperactivity and poorer academic performance [5-8]. In addition, short term changes in biological markers and alterations in hormonal activity are increasingly reported in adolescents with sleep problems $[9,10]$. Finally, adolescents with reduced sleep duration appear more likely than other children to be overweight or obese [11], through associated alterations to metabolic markers of appetite regulation, insulin and glucose utilisation [12].

\footnotetext{
*Address correspondence to this author at the Appelton Institute, Central Queensland University, Australia; Tel: +61 414700 953;

Fax:+618 83784532; E-mail: s.blunden@cqu.edu.au
}

In addition, there is considerable debate [13] and some concern about what some report as a decrease in sleep duration over the last twenty years $[14,15]$. Reasons for suggested decreases in sleep include sleep being seen as not important and being sacrificed to socialising [16] employment, technology [17] and early school start times [18].

As a consequence, there have been some suggestions that young people do not get sufficient sleep. Whilst guidelines for what is 'sufficient' sleep duration are based on scant evidence [13] and there are suggestions that a threshold effect for sufficient sleep may need further consideration [19], there nonetheless appears a general consensus, that adolescents report significant sleepiness [18, 20-23]. Adolescents need to awaken feeling well rested and alert to benefit from daily activities. According to Carskadon and colleagues [18], the average adolescent requires approximately 9 hours of sleep (although others suggest less [19]). However, if the former guideline is correct, it is worth noting that only one in five adolescents in the United States of America obtains this amount on school nights with nearly one-half (45\%) sleeping for only 8 hours on such nights [24]. In Australia, 17\% of adolescents do not meet the nine hour sleep duration requirement [25]. In fact, based on these data for sleep duration and with increasingly delayed bedtimes [15], sleep loss 
is emerging as a worldwide adolescent problem that has been reported across countries and cultures [14].

Despite the significant impact of sleep problems reported above, awareness in the community is low [26-28]. It has also been recognised that sleep education programs may be part of a solution in addressing this deficiency [29]. Sleep education programs have been developed and trialled in Brazil [30], the United States of America (USA) [31, 32], Italy [33], Australia [34-36], and New Zealand [37]. These studies have utilised different sleep education programs, largely developed for the purpose of each specific study and so it is difficult to compare and evaluate their efficacy. In addition, based on the published literature, most programs have only been trialled once. Two exceptions are the Sleep Smart program in the USA, which has undertaken two trials $[31,32]$ and the Australian Centre for Education in Sleep program (ACES) which has been utilised in three trials [34, $37,38]$. No study to date has compared in detail any sleep education program across separate trials.

This paper presents a comparison of the ACES sleep education trials in two Australian high schools [34] and one New Zealand high school [37]. By comparing the same program, which has been delivered in three separate trials, the opportunity arises to evaluate the efficacy of the ACES program more broadly. In addition, and perhaps more importantly, given that sleep education in its infancy and efforts are moving forward internationally, comparing the same program across trials may further our understanding of sleep education more generally.

\section{MATERIALS AND METHODOLOGY}

\section{Materials}

The ACES program contains 3 components - the school based power point presentations (4 sessions), the student workbook and the teachers training manual. Each of the four power point sessions last approximately 50 minutes in length and range between 10-22 slides per session.

\section{ACES Session Content}

Prior to beginning at baseline $\left(\mathrm{T}_{0}\right)$, participants are requested to complete sleep knowledge questionnaires (see below in Assessment section) used to evaluate any changes in sleep knowledge post intervention. The first session then introduces sleep in general with information on how, why and how much we sleep. This includes information regarding sleep architecture, sleep physiology, respiratory and non respiratory sleep disorders, the importance of sleep and the effects of insufficient sleep. Students are introduced to the concept of measuring their own sleep and are asked to complete a 7 day sleep diary for homework. Students record time to bed, time taken to fall asleep (sleep onset latency), time awake over night after sleep onset (WASO) from which calculations of Total Sleep Time (TST) can be undertaken, as well as a self assessment of whether they perceive their sleep to be restorative and restful.
In session 2, after revision of session 1, student diaries are examined, leading to a discussion of those who have sleep difficulties and those who don't. Discussion of adolescent changes in sleep patterns with an explanation of sleep phase delay and its relationship to melatonin secretion, is a principal component of this session. The effects of insufficient sleep on this age group are discussed. Sleep hygiene is introduced and students are asked to complete a sleep hygiene questionnaire for homework, accessing the sleep websites (www.sleepfoundation.org and www.sleepeducation. net.au) for more information.

In session 3, sleep hygiene is assessed, tips for improving sleep are discussed coupled with a general revision of previous sessions. The session includes a section on the benefits of strategic napping.

In session 4 , the effects of insufficient sleep on mood, anxiety, stress and performance are presented in greater detail. Other topics, such as parasomnias (dreams, nightmares and sleep walking) are discussed. Students complete the sleep knowledge questionnaires on completion of the sessions as a follow up $\left(\mathrm{T}_{1}\right)$.

\section{Student Workbook}

A workbook is given to each student which summarises and highlights the content of the 4 power point presentations. Student workbooks reference specific sections of the presentations and encourage greater engagement in the subject matter via group discussion, quizzes, web based resources and activities, sleep diaries, sleep hygiene questionnaires and case studies. Selected slides from the power point sessions are included.

\section{Teacher's Manual}

Teachers are given a 50 page manual which covers general information about sleep with a particular focus on adolescent sleep. Step by step explanations of the power point presentations with accompanying notes and examples, as well as answers to student workbook quizzes, homework and classroom exercises are features of the teacher's manual.

\section{Assessment Tools}

As there are no standardised nor published evaluation tools or sleep knowledge questionnaires for sleep education programs, three evaluation tools were developed by the author specifically for the ACES program. To assess sleep knowledge, two tools can be used: a True /False Questionnaire (TFQ) of 15 questions and a short answer Sleep Knowledge Questionnaire (SKQ). In the TFQ, students are asked to answer 'True" or 'False' to questions such as "Dreams occur in NREM sleep" (See Appendix 1). The Sleep Knowledge Questionnaire has 8 questions requiring short answers such as "Sleep deprivation can lead to many consequences. List five (5)". This latter questionnaire has a maximum score value of 25 points. All questions in both the TFQ and the SKQ are based on session content and workbook exercises. 
Qualitative evaluation of the program can be undertaken with the anonymous Program Evaluation Sheet (PES), developed after consultation with students and teachers. The PES asks with a Yes or No format whether the program is informative, educational, a waste of time, too long, not long enough, entertaining, boring, needing more information, helpful or difficult to understand.

\section{Parent Booklet}

A 21 page illustrated booklet entitled "Parenting with your child's sleep in mind" is available as an adjunct to the student program and contains information, slides and resources that mirror the session content of the ACES classroom sessions. The booklet is aimed at simultaneously increasing sleep knowledge for parents.

\section{AUSTRALIAN TRIAL}

\section{Participants}

Two consecutive trials of the high school program were delivered in Australia. The first (AUS1) was delivered to 22 students in Year 10 (Mean age: 15y.5mths; range 14y.9mths $-15 \mathrm{y} .10 \mathrm{mths} 55 \%$ female) attending public school \#1. The sessions were incorporated into the health and psychology classes and were delivered by the researcher (SB). The second trial (AUS2) was delivered to 47 year students in year 10 (Mean age $15 \mathrm{y} .4 \mathrm{mths}$, range $14 \mathrm{y} .9 \mathrm{mths}-15 \mathrm{y} .10 \mathrm{mths}, 46 \%$ females) as part of a health and personal development curriculum component in public School \#2.

\section{Procedure and Design}

Following AUS1, which was delivered by the researcher (SB), the responses from the Program Evaluation Sheet (PES) from students and teachers were examined to assess content and deliverability. Comments to improve the program were invited. These evaluations resulted in several changes. Clarification of some topics (e.g. definitions of circadian rhythm and parasomnias), more information about napping, dreaming and the effects of alcohol and drugs on sleep were requested as well as more interactive work and relaxation exercises. These were all incorporated into AUS2 with the relaxation training added into an optional extra session. For AUS2, five teachers from the same (second) school were trained in the program with a 5 hour training session complete with teacher training manual, CD-Rom and program summary. Teachers then delivered the program in four x 50 minute sessions over a period of 4 weeks. The ACES program was delivered as described above for AUS2.

Both Australian pilot trials were pre - post cross sectional uncontrolled designs with two principal aims: first - to assess feasibility of delivery and acceptability of content: second to assess changes in sleep knowledge as measured by the True/False Questionnaire (TFQ). The TFQ was completed at baseline $\left(\mathrm{T}_{0}\right)$ and directly after the intervention at $T_{1}(4$ weeks).

Ethics permission was gained from both the University of South Australia and the South Australian Department of Education and Children's Services and informed consent was acquired from participants and their guardians.

\section{RESULTS OF AUSTRALIAN TRIALS 1 AND 2 (AUS1, AUS2)}

Students in AUS1 completed both the TFQ and the SKQ but in AUS2, due to time constraints, only the TFQ was utilised. Therefore to facilitate comparisons with the New Zealand trial (NewZ) only the TFQ data are reported here. As shown in Table 1, sleep knowledge significantly im-

Table 1. Comparison of ACES Australian (AUS1 and AUS2) and New Zealand (NewZ) Trials

\begin{tabular}{|c|c|c|c|}
\hline & AUS1 & AUS2 (After Amendments) & NewZ (With Amendments) \\
\hline $\mathrm{N}$ & 22 (Mean age: 15.5 years; $55 \%$ female) & 47 (Mean age 14.9 years, $46 \%$ female) & 29 (Mean age: 14.7 years, $45 \%$ female) \\
\hline $\begin{array}{l}\text { Baseline }\left(\mathrm{T}_{0}\right) \text { to Follow } \\
\text { up }\left(\mathrm{T}_{1} \text { and } / \text { or } \mathrm{T}_{2}\right)\end{array}$ & 4 weeks & 4 weeks & $\begin{array}{l}\mathrm{T}_{1} 6 \text { weeks } \\
\mathrm{T}_{2} 10 \text { weeks }\end{array}$ \\
\hline Study design & $\begin{array}{l}\text { Uncontrolled repeated measures pre post } \\
\text { pilot evaluation }\end{array}$ & $\begin{array}{l}\text { Uncontrolled repeated measures pre } \\
\text { post pilot evaluation }\end{array}$ & $\begin{array}{l}\text { RCT, } 2 \text { conditions: Experimental ( } \mathrm{n} \\
=15) \text { vs control }(\mathrm{n}=14) \text { pre post evalua- } \\
\text { tion }\end{array}$ \\
\hline Delivery & $\begin{array}{l}4 \times 50 \text { minute sessions delivered by } \\
\text { author }\end{array}$ & $\begin{array}{l}4 \times 50 \text { minute sessions delivered by } \\
\text { teachers }\end{array}$ & $\begin{array}{l}6 \times 50 \text { minute sessions delivered by } \\
\text { teachers }\end{array}$ \\
\hline Assessment tools & $\mathrm{TFQ}+\mathrm{SKQ}$ & TFQ & TFQ + 7-day sleep diary \\
\hline Results & $\begin{array}{l}\uparrow \text { Sleep knowledge }(\mathrm{p}<0.001) \\
\text { Sleep duration (not measured) } \\
100 \% \text { wanted inclusion in curriculum } \\
90 \% \text { educational } \\
95 \% \text { informative } \\
9 \% \text { found it boring }\end{array}$ & $\begin{array}{l}\uparrow \text { Sleep knowledge }(\mathrm{p}=0.005) \\
\text { Sleep duration (not measured) } \\
97 \% \text { educational } \\
97 \% \text { informative } \\
51 \% \text { found it boring }\end{array}$ & $\begin{array}{l}\leftrightarrow \text { Sleep knowledge }(\mathrm{ns}) \\
\uparrow \text { Sleep duration }(\mathrm{p}=0.04 \text { whole week; } \\
\mathrm{p}=0.02 \text { weekends) } \\
100 \% \text { educational } \\
93 \% \text { informative } \\
29 \% \text { found it boring }\end{array}$ \\
\hline
\end{tabular}

TFQ = True False Questionnaire; $T_{1}=$ Time 1, after sleep intervention $; T_{2=10}$ weeks after $T_{1}$ 
proved in both AUS1 and AUS2 (all $p<0.05$ ).

Specifically in AUS1 on the TFQ at $\mathrm{T}_{0}$, all students scored $<40 \%$. At $\mathrm{T}_{1}, 100 \%$ students significantly improved scores $(t=8.337, p<0.001)$, with all students scoring $>40 \%$ and $63 \%(14 / 22)$ scoring $>65 \%$. For AUS2, the TFQ pre scores were higher at $\mathrm{T}_{0}$ with only $9 \%(3 / 33)$ scoring $<40 \%$ but still only $26 \%(8 / 33)$ students scoring over $65 \%$. For AUS2 $\mathrm{T}_{1}, 87 \%(29 / 33)$ of students significantly improved their scores on the TFQ, $(t=4.67, p=0.005)$ with $87 \%$ scoring $>65 \%$.

The vast majority of students considered the program to be acceptable. Specifically, 90-97\% found it educational and 95-97\% informative in AUS1 and AUS2 respectively, while $100 \%$ (AUS1) and $88 \%$ (AUS2) stated that it should be included in the curricula. Despite this, $9 \%$ of students in AUS1 and 51\% in AUS2 said it was boring.

Teachers were asked to comment on the feasibility of delivering this program. In general, teachers $(100 \%)$ were supportive of the program and recognised both the importance of the information and how positively the students engaged with it. Qualitative analysis of the open ended comments suggested two main themes - the logistics of delivery, including time taken for training, and time allocation needed to deliver the program in already crowded curricula. Changes in parental knowledge or attitudes were not assessed.

\section{NEW ZEALAND TRIAL (NEWZ)}

\section{Participants}

This study has been described in detail elsewhere [37] so only details relevant to this comparison are presented here. In short, 29 high school students (Mean age 14y.6mths; range $13 \mathrm{y} .3 \mathrm{mths}-16 \mathrm{y} .9 \mathrm{mths}$ ) from two classes ( $45 \%$ female) were randomised into either a sleep education intervention programme $(\mathrm{n}=15)$ or a control $(\mathrm{n}=14)$ group (curriculum as usual). The sample included a large proportion of Māori $(31 \%)$ and Pacific (14\%) students.

\section{Procedure and Design}

The program was delivered by one health education teacher trained in the ACES program, during 6 classrooms sessions over 6 weeks. While similar in delivery to the Australian studies, minor changes were made to ensure the suitability for the New Zealand environment. First, total duration of the intervention was 6 weeks instead of 4 weeks as teach- ers divided the first week's slides into two sessions. Second, information on the effect of alcohol and drugs on sleep, depression/anxiety and sleep, and optional relaxation exercises were omitted as the programme ran over time. Finally, the parent workbook was sent home with student's parents although changes to parental knowledge were not assessed.

While all participants completed a range of other non sleep assessments (see [37]), only sleep duration and knowledge are reported here to facilitate comparisons with the Australian trials. Assessments were undertaken at baseline $\left(\mathrm{T}_{0}\right)$, immediately post-intervention $\left(\mathrm{T}_{1}\right)$ and 10 -week post intervention $\left(T_{2}\right)$ (See Table 1). The control group received curriculum as usual with a condensed version of the intervention at the completion of the trial.

The New Zealand trial was a feasibility study and a randomised control pilot trial. Ethical approval was provided by Northern X Regional Ethics Committee (NTX/09/07/067) and informed consent was acquired from participants and their guardians.

The overall aim was to adapt and test the feasibility of the ACES sleep education program for delivery in New Zealand schools building on the Australian trials by assessing changes to sleep knowledge but in addition assessing a range of sleep patterns.

\section{RESULTS OF NEW ZEALAND TRIAL (NEWZ)}

Changes in sleep knowledge were assessed with the TFQ but not reported in the original paper [37]. Communications with the author suggested that $40 \%$ improved their score but also $40 \%$ decreased their score while $20 \%$ had no change, which resulted in an overall non significant result $(p>0.05)$. Mean scores for each time point are presented in Table 2.

For sleep duration, at $\mathrm{T}_{0}$, overall both groups reported similar sleep durations $[8: 41( \pm 1: 40)$ and 8:39 $( \pm 0: 57)$ respectively. After the intervention, ANOVA suggests that those in the intervention obtained significantly $(p=0.04)$ more sleep for the whole week compared to controls at $T_{1}$ [9h:20mins $( \pm 1: 03)$ vs $8 \mathrm{~h}: 08$ mins $( \pm 1: 46)]$ which was sustained at $\mathrm{T}_{2}$ [9h:32mins $( \pm 1: 15)$ vs $\left.8: 28( \pm 1: 14)\right]$. This improvement was more pronounced on the weekends (Friday and Saturday) with the intervention group sleeping longer than the control group at $T_{1}[9: 28( \pm 1: 18)$ vs 7:51 $( \pm 1: 41)]$ which was also sustained at $T_{2}[9: 48( \pm 1: 31)$ vs $8: 16( \pm 1: 40)$; $p=0.02]$.

Overall, the acceptability of the programme was high and similar to both Australian trials with all students reporting that it was educational $(100 \%)$ and moist reporting that it

Table 2. Mean (SD) scores of the TFQ for NewZ

\begin{tabular}{|c|c|c|c|}
\hline $\begin{array}{c}\text { Sleep Knowledge } \\
\text { NewZ }\end{array}$ & $\begin{array}{c}\text { Intervention } \\
\mathbf{( N = 1 5 )}\end{array}$ & $\begin{array}{c}\text { Control } \\
(\mathbf{n = 1 4 )}\end{array}$ & $\begin{array}{c}\text { Total } \\
(\mathbf{n}=\mathbf{2 9})\end{array}$ \\
\hline \hline $\mathrm{T}_{1}$ & $10.40(2.03)$ & $10.50(1.61)$ & $10.45(1.80)$ \\
\hline $\mathrm{T}_{2}$ & $11.13(2.03)$ & $10.36(1.78)$ & $10.79(1.89)$ \\
\hline $\mathrm{T}_{3}$ & $10.87(1.64)$ & $10.14(1.51)$ & $10.57(1.60)$ \\
\hline
\end{tabular}


was informative (93\%). Data were not available for whether students thought it should be included in the curricula. The programme was perceived as boring by $29 \%$ of students.

When interviewed, teachers reported that although they deemed the program useful, they had insufficient resources with regard to curriculum time and the staff to contribute to the programme. The teacher involved reported that the training and delivery were time consuming.

\section{DISCUSSION}

This is the first paper to present data on three trials of the same sleep education program. Whilst the trials were undertaken in different countries, had slightly different content, duration and demographics, findings suggest that this sleep education programme can improve sleep knowledge and/or sleep duration in adolescents. Given the increasing literature on the effects of problematic sleep during adolescence, these data raise several important issues regarding the future of sleep education in this age group.

In terms of sleep knowledge, the Australian trials found significant changes while New Zealand found non significant changes. There may be some factors to consider which may have impacted this difference in sleep knowledge. The Australian and New Zealand trials delivered the same program and were all trained according to the same training manual. However, the programs were delivered by different teachers and for the New Zealand trial there were minimal changes (exclusion of sections on drugs and alcohol depression/anxiety and sleep, and optional relaxation exercises) which were principally to enhance acceptability. As there was only one question in the TFQ about any of these topics it is unlikely that these differences in content resulted in the findings for sleep knowledge. Possible variations in how teachers delivered and engaged may also have influenced acquisition of knowledge despite all teachers having the same training manual (a problem that may well be reduced with larger trials and more significant sample sizes). It should be noted that in all trials, the students and teachers reported similar levels of interest in the program suggesting considerable engagement in the program. Other factors that may account for discrepancy in sleep knowledge may be differences in the sample demographic. The New Zealand cohort has a large percentage of indigenous students (Māori). The study did not randomise by ethnicity nor was it sufficiently powered to analyse results by ethnicity and so it is not possible to evaluate any effects on outcome variables.

It is also possible that the differences in sleep knowledge outcomes were due to the psychometric properties of the TFQ - that is, the TFQ items did not measure what they were intended to, [39] although this hypothesis would not account for the results in Australia. Perhaps this problem may be alleviated by analysing each item pre vs post individually, as has been reported in a study by Azevedo and colleagues [40] or by developing a sleep knowledge questionnaire with a factorial structure.

It should be noted that no standardised assessment measures exist for testing sleep knowledge in this age group and studies are therefore obliged to construct and develop their own. Interestingly, most studies measuring sleep knowledge with their own questionnaires have reported an increase in sleep knowledge post intervention [33, 35, 36, 40, 41]. The conclusions from this paper and previous work therefore highlight the need for use of a standard sleep knowledge measure.

A second important finding from this study is that sleep duration was improved in the New Zealand study suggesting that the delivery of sleep education can result in positive sleep behaviour change. Sleep duration increases have also been reported in only one previous trial [32] but most studies have found none. Indeed many have not measured sleep duration directly.

Furthermore, in the trials described here, given their pilot nature, sleep was only assessed subjectively. The use of actigraphy, known as an adequate measure of sleep duration [42], should be utilised in future programs to assist in evaluating if the self-reported changes after sleep education are apparent objectively. Measuring sleep objectively will enable a greater understanding of whether sleep education is efficacious (or not) in changing sleep behaviour. This also highlights a broader issue.

All sleep educations programs, like all health education programs, aim to change behaviour and these trials of the ACES sleep education program were based on the presumption that, all else being equal, sleep education will positively influence sleep behaviour. However, many theoretical models suggest that knowledge alone is rarely sufficient to achieve behaviour change. According to social cognitive models such as the theory of planned behaviour [43] behaviour is influenced by intentions and perceived control of the behaviour and the importance placed on the intervention by significant others [43]. That is, whether recipients of the sleep education perceive the behaviour to be desirable, favourable or worthwhile and the degree to which individuals, such as relatives, friends, or colleagues, condone the healthy sleep behaviour [43, 44]. In the New Zealand trial, parent workbooks were sent home in an attempt to include parent/guardians in the knowledge acquisition process and this may have been a contributing factor to the changes in sleep duration observed in that trial. Sleep is one of those behaviours of which parents gradually loosen their control as a child moves into adolescence. An adolescent who has poor sleep habits may not improve them without parental guidance, a factor that has been confirmed in a recent trial [45] thus parents should be informed about sleep hygiene. Although parental opinion or behaviours were not measured, it could be presumed that this may have been a beneficial addition to the sleep education program. Future studies should include some parental report measures to understand this more clearly.

A final point that this comparison brings to light is that of acceptability. Qualitative evaluations suggested that both Australian and New Zealand participants and teachers believed this to be an important area for future development. However, all trials noted that the program was time intensive both for the students and for the teachers, particularly when the teachers were trained to deliver the program themselves. Adequate resourcing in terms of time and financial support, which may be dependent on the salience attributed to sleep education in the first instance, would appear to be an impor- 
tant issue before any sleep education intervention can be scaled up. Including sleep education into already crowded curricula could be assisted by integrating sleep modules into other core school subjects such as science, health and psychology. Finding alternative or adjunct methods of delivery may be helpful to overcome time and curriculum restraints, for example, external facilitator-led programs or use of the online resources which are beginning to be available (e.g. www.sleepfoundation.org: www.sleepeducation.net.au). Further investigations and consultations with teaching professionals and the students themselves would be beneficial here.

\section{CONCLUSION}

This paper show promising results for the ACES sleep education program in Australian and New Zealand adolescents. Future trials of sleep education programs should take into consideration the issues which have arisen from this comparison of the ACES program such as larger sample sizes and further use of a randomised control design. Stan- dard sleep knowledge measures with factor structures should be considered which will improve assessment through psychometric validity. Resources and time allocations need to be considered in the context of current loaded school curricula and creative efforts to embed sleep education into school programs should be considered if this is to be embraced. Finally, measurement of sleep duration should be objectified and could explore whether parental involvement may increase the opportunities for improved sleep behaviour change.

\section{CONFLICT OF INTEREST}

The author(s) confirm that this article content has no conflicts of interest.

\section{ACKNOWLEDGEMENT}

None declared.

\section{APPENDIX 1}

\section{True/False (Sleep Knowledge) Questionnaire (TFQ)}

Please answer the following questions by ticking either true or false

\begin{tabular}{|c|c|c|c|}
\hline & True or False? & True & False \\
\hline 1 & Tired teenagers do poorly in school and have problems socially. & & \\
\hline 3 & Alcohol, even small amounts, give you a good night's sleep. & & \\
\hline 4 & NREM sleep has four stages. & & \\
\hline 6 & Teenagers need more sleep than their parents. & & \\
\hline 7 & Full sleep cycles go for about 30 minutes. & & \\
\hline 8 & When you are tired your reactions are exactly the same as when you are not tired. & & \\
\hline 9 & Sleep deprivation does not effect concentration. & & \\
\hline 12. & When we fall asleep we usually go into REM sleep. & & \\
\hline 13 & Sleeping in late on weekends is normal for teenagers. & & \\
\hline 14 & Snoring is an indicator of sleep apnea. & & \\
\hline 15 & Dreams occur in NREM sleep. & & \\
\hline
\end{tabular}

\section{REFERENCES}

[1] AASM. International classification of sleep disorders: Diagnostic and coding manual. $2^{\text {nd }}$ ed. Westchester, IL. : American Academy of Sleep Medicine 2005.

[2] Anders T, Eiben L. Pediatric sleep disorders: a review of the past 10 years. J Am Acad Child Adolesc Psychiatry 1997; 36(1): 9-20.

[3] Lozoff B, Wolf A, Davis N. Sleep problems seen in pediatric practice. Pediatrics 1985; 75(3): 477-83.

[4] Kahn, A, Van de Merckt C, Rebuffat E, et al. Sleep problems in healthy preadolescents. Pediatrics 1989; 84(3): 542-6.

[5] Wolfson AR, Carskadon MA. Sleep schedules and daytime functioning in adolescents. Child Dev 1998; 69(4): 875-87.
[6] Blunden SL, Lushington K, Lorenzen B, Martin J, Kennedy D. Neuropsychological and psychosocial function in children with a history of snoring or behavioral sleep problems. J Pediatr 2005; 146(6): 780-6.

[7] Owens J, Opipari L, Nobile C, Spirito A. Sleep and daytime behavior in children with obstructive sleep apnea and behavioral sleep disorders. Pediatrics 1998; 102(5): 1178-84.

[8] Carskadon M, Acebo C, Jenni O. Regulation of adolescent sleep: implications for behavior. Ann N Y Acad Sci 2004; 1021: 276-91.

[9] Blunden SL. Beebe DW. The contribution of intermittent hypoxia, sleep debt and sleep disruption to daytime performance deficits in children: Consideration of respiratory and non-respiratory sleep disorders. Sleep Med Rev 2006; 10(2): 109-18. 
[10] Kryger M, Roth T, Dement WC. Principles and practices of sleep medicine. $2^{\text {nd }}$ ed. Philadelphia: W.B. Saunders Company 1994.

[11] Gupta N, Mueller WH, Chan W, Meininger JC. Is obesity associated with poor sleep quality in adolescents? Am J Hum Biol 2002; 14(6): 762-8.

[12] Spiegel K, Leproult R, Van Cauter E. Impact of sleep debt on metabolic and endocrine function. Lancet 1999; 354: 1435-9.

[13] Matricciani L, Olds T, Williams M. A review of evidence for the claim that children are sleeping less than in the past. Sleep 2011; 34(05): 651-9.

[14] Olds T, Blunden SL, Petkov J, Forchini F. The relationships between sex, age, geography and sleep duration in adolescents: a meta-analysis of data from 23 countries. Sleep Med Rev 2010; 14: 371-8.

[15] Dollman J, Ridley K, Olds T, Lowe E. Trends in the duration of school-day sleep among 10- to 15-year-old South Australians between 1985 and 2004. Acta Paediatr 2007; 96(7): 1011-4.

[16] Adam E, Snell EK, Pendry P. Sleep timing and quantity in ecological and family context: A nationally representative timediary study. J Fam Psychol 2007; 21(1): 4-19.

[17] Van den Bulck J. Television viewing, computer game playing and internet use and self reported time in bed and ti e out of bed in secondary school children. Sleep 2004; 27(1): 101-4.

[18] Carskadon M, Wolfson A. Adolescent sleep patterns, circadian timing, sleepiness at a transition to early school days. Sleep 1998; 21(8): 871-81.

[19] Eide E, Showalter M. Sleep and student acheivement. East Econ J 2012; 1:1-13.

[20] Blunden S, Hoban T, Chervin RD. Sleepiness in children. Sleep Med Clin 2006; 1(1):105-18.

[21] Fallone GJ, Owens J, Deane J. Sleepiness in children and adolescents: clinical implications. Sleep Med Rev 2002; 6(4): 287306.

[22] Millman RP. Excessive sleepiness in adolescents and young adults: causes, consequences and treatment strategies. Pediatrics 2005; 115(6): 1774-86.

[23] Moore M, Meltzer LJ. The sleepy adolescent: causes and consequences of sleepiness in teens. Paediatr Respir Rev 2008; 9(2): 114-21.

[24] NSF. Sleep in America Poll. Washington, DC: N.S. Foundation 2007.

[25] Olds T, Maher C, Blunden S, Matricciani L. Normative data on the sleep habits of Australian adolescents. Sleep 2010; 33(10): 1381-8.

[26] Blunden S, Lushington K, Lorenzen B, Ooi T , Fung F, Kennedy D. Are sleep problems under-recognised in general practice? Arch Dis Child 2004; 89(8): 708-12.

[27] Archbold KH, Pituch KJ, Panahi P, Chervin RD. Symptoms of sleep disturbances among children at two general pediatric clinics. J Pediatr 2002; 140(1): 97-102
[28] Owens JA, Veasey SC, Rosen RC. Physician, heal thyself: sleep, fatigue, and medical education. Sleep 2001; 24(5): 493-5.

[29] Gruber R, Weibe ST, Wells SA, Cassof J, Monson E. Sleep and academic success: mechanisms, empirical evidence and interventional strategies. Adolesc Med 2010; 21: 522-41.

[30] De Sousa I, Araújo JF, De Azevedo CVM. The effect of a sleep hygiene education program on the sleep-wake cycle of Brazilian adolescent students. Sleep Biol Rhythms 2007; 5(4): 251-8.

[31] Rossi C, Campbell AL, Vo OT, Charron T, Marco CA, Wolfson AR. Middle school sleep-smart program: A pilot evaluation. Sleep 2002; 25: A279-9.

[32] Vo O, LeChasseur K, Wolfson A, Marco C. Sleepy pre-teens: Second pilot of sleep-smart program in 7th graders. Sleep 2003; 26: A411-2.

[33] Cortesi F, Giannotti F, Sebastiani T, Bruni O, Ottaviano S. Knowledge of sleep in Italian high school students: pilot-test of a school-based sleep educational program. J Adolesc Health 2004; 34(4): 344-51.

[34] Blunden S. The implementation of a sleep education program in adolescents. Sleep Biol Rhythms 2007; 5(1): A31.

[35] Moseley L, Gradisar M. Evaluation of a school-based intervention for adolescent sleep problems. Sleep 2009; 32(3): 334-41.

[36] Cain N, Gradisar M, Moseley L. A motivational school-based intervention for adolescent sleep problems. Sleep Med 2011; 12(3): 246-51.

[37] Kira G, Maddison R, Hull M, Blunden S, Olds T. Sleep education improves adolescent sleep: a randomised controlled pilot study. J Paediatr Child Health 2011. in press.

[38] Blunden S. The implementation of a sleep education program in primary school children. Sleep Biol Rhythms 2007; 5(1): A32.

[39] Tabachnick B, Fidell L. Using multivariate statistics. Needham Heights, USA: Allyn \& Bacon 2001

[40] Azevedo C. Teaching chronobiology and sleep habits in school and university. Mind Brain Educ 2008; 2(1): 34-46.

[41] Bakotic M. Radosevic-Vidacek B, Kosec A. Educating adolescents about healthy sleep: Experimental study of effectiveness of educational leaflet. Public Health 2008; 50: 174-81.

[42] Sadeh A, Acebo C. The role of actigraphy in sleep medicine. Sleep Med Rev 2002; 6(2): 113-24.

[43] Ajzen I. The theory of planned behavior. Organ Behav Hum Decis Process 1991; 50: 179-211.

[44] Ajzen I, Saunders J, Davis LE, Williams T. The decision of African American students to complete high school: An application of the theory of planned behavior. J Educ Psychol 2002; 94: 810-9.

[45] Short M, Gradisar M, Wright H, Lack LC, Dohnt H, Carskadon MA. Time for bed: parent-set bedtimes associated with improved sleep and daytime functioning in adolescents. Sleep 2011; 34(6): 797-800.

(C) Blunden et al.; Licensee Bentham Open.

This is an open access article licensed under the terms of the Creative Commons Attribution Non-Commercial License (http://creativecommons.org/licenses/by-nc/3.0/) which permits unrestricted, non-commercial use, distribution and reproduction in any medium, provided the work is properly cited. 